\title{
Laparoscopic Excision of Leiomyoma of the Round Ligament of the Liver
}

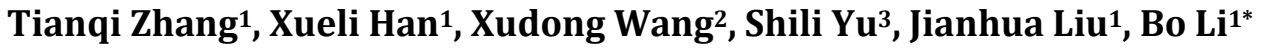 \\ ${ }^{1}$ Department of Radiology, The Second Hospital of Jilin University, Changchun, China \\ ${ }^{2}$ Department of Gastrointestinal Surgery, The Second Hospital of Jilin University, Changchun, China \\ ${ }^{3}$ Department of Pathology, The Second Hospital of Jilin University, Changchun, China \\ Email: `553906125@qq.com
}

How to cite this paper: Zhang, T.Q., Han, X.L., Wang, X.D., Yu, S.L., Liu, J.H. and Li, B. (2017) Laparoscopic Excision of Leiomyoma of the Round Ligament of the Liver. Advances in Computed Tomography, 6, 17-20.

https://doi.org/10.4236/act.2017.63003

Received: July 23, 2017

Accepted: August 12, 2017

Published: August 15, 2017

Copyright $\odot 2017$ by authors and Scientific Research Publishing Inc. This work is licensed under the Creative Commons Attribution International License (CC BY 4.0).

http://creativecommons.org/licenses/by/4.0/

\begin{abstract}
Leiomyoma of the round ligament of the liver is a very unusual tumor, and it shows nonspecific manifestations both in symptom and radiographic characterization. Herein, we report the case of leiomyoma which CT post-processing technique can directly exhibit the origin of the lesion. With radiological diagnosis, laparoscopic excision of the leiomyoma is carried out. Histopathology and immunohistochemical staining confirmed the leiomyoma of the round ligament. This case presents information to expand our knowledge focusing on the role of the CT post-processing technique before laparoscopic excision.
\end{abstract}

\section{Keywords}

Leiomyoma, Round Ligament of the Liver, Aparoscopic Excision, Computed Tomography

\section{Introduction}

Leiomyoma of the round ligament of the liver is a very unusual tumor [1]. It should be differentially diagnosed from the gastrointestinal tract tumors. Although symptom and pattern of enhanced CT are nonspecific, post-processing reconstruction technique provides the origin of the lesion in this case. With radiological diagnosis, laparoscopic excision of the leiomyoma is carried out. To the best of our knowledge, we present the first enhanced CT imaging which directly showing leiomyoma arising from the round ligament of the liver, and it is also the first reported case which treated with laparoscopic excision.

\section{Case Study}

A 48-year-old woman was admitted in department of gastrointestinal surgery, 
with history presented with last two months of standing hypogastric pain (Table 1). Physical examination revealed a tumor of $8 \mathrm{~cm} \times 8 \mathrm{~cm}$ with abdominal tenderness and distension in the hypogastric region. Serum tumor marker (carbohydrate antigen) level was $4.11 \mathrm{ng} / \mathrm{ml}$ which higher than normal range $(<3.0$ $\mathrm{ng} / \mathrm{ml}$ ). For further diagnosis and treatment, triphasic CT enhancement of whole abdomen was performed. As shown in Figure 1(a), coronal section exhibited a $8.0 \mathrm{~cm} \times 7.3 \mathrm{~cm}$ low density lesion (white star) with smooth margin, triphasic CT scan showed gradually enhancement in Figures 1(b)-(d), with CT value of $35 \mathrm{Hu}$ in arterial phase, $43 \mathrm{Hu}$ in portal phase and $52 \mathrm{Hu}$ in delayed phase, vessel enhancement (white curved arrow) was seen in the lesion which indicated artery supply. It is difficult to analyze origin of the lesion in axial and coronal section. However, as shown in Figures 1(b)-(d), sagittal section clearly presented the origin, which closely connected with the lower portion of the round ligament of liver. Figure 1(b) showed the vessel enhancement in the round ligament, which supplied to the lesion. The round ligament showed same enhancement pattern to the liver in Figure 1(d), which indicated origin of liver. Radiographic diagnosis indicated a benign mass on the round ligament. Subsequently, laparoscopic excision was planned. As shown in Figure 2(a), the mass appeared connected with the round ligament of the liver extending to the anterior abdominal wall. The lesion was dissected from the round ligament and surrounding structures using ultracision harmonic scalpel. Histopathology proved leiomyoma with mucoid degeneration and necrosis in Figure 2(b). Immunohistochemical staining was positive for smooth muscle actin (SMA), Desmin in Figure 2(c) and Figure 2(d). Post-operative course was stable, three days later, the patient was discharged.

Table 1. Sociodemographic and clinical characteristics of this patient.

\begin{tabular}{cc} 
Age & 48 -year-old \\
Gender & woman \\
Clinical characteristics & standing hypogastric pain \\
\hline
\end{tabular}

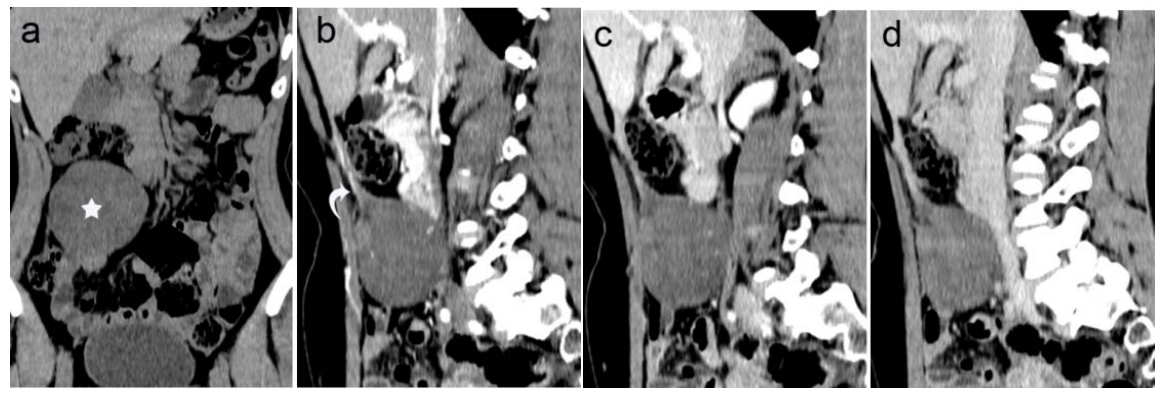

Figure 1. Coronal and sagittal section of triphasic CT scan. A exhibited a $8.0 \mathrm{~cm} \times 7.3 \mathrm{~cm}$ low density lesion (white star) with smooth margin, triphasic CT scan showed gradually enhancement in (b)-(d). (a) Showed a round soft tissue (white star) with smooth margin. (b) Showed the vessel enhancement in the round ligament (white curved arrow), (c) Showed the lesion enhanced gradually, (d) Showed origin of liver. 

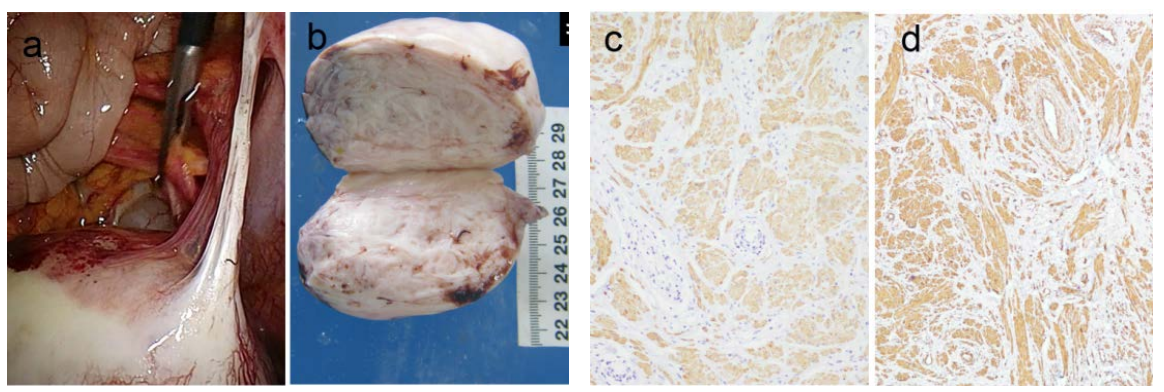

Figure 2. Laparoscopic excision and pathology of leiomyoma. (a) Showed the mass appeared connected with the round ligament of the liver extending to the anterior abdominal wall, (b) Showed the histopathology proved leiomyoma with mucoid degeneration and necrosis, Immunohistochemical staining was positive for smooth muscle actin (SMA), Desmin in (c), (d).

\section{Discussion}

The round ligament of liver represents the remnant of fetal umbilical vein, and the umbilical vein is entirely obliterated and replaced by round ligament within one week of birth [2]. Leiomyoma is mesenchymal tumor which originates in the intestinal muscularis propria or the tunica media of blood vessels [3]. As shown in Figure 2, the lesion in our case connects with round ligament of liver, which indicates the tumor originates tunica media of blood vessels (umbilical vein). The leiomyoma of round ligament in earlier stage is usually asymptomatic, with lesion growth, palpable mass or abdominal pain may appear. It should be differentiated with benign lesion of round ligament, such as mesothelial cyst [4]. The growth of leiomyoma is expanding pattern rather than invasion [5]. Radiological findings are nonspecific, CT imaging of this case exhibits gradual enhancement in portal and delayed phases. However, post-processing reconstruction technique of CT is critical to evaluate location of the lesion. In this case, the location is clearly shown in sagittal section rather than traditional axial section. The final diagnosis should be proved by histopathology, and further confirmed by immunohistochemistry with positive results for smooth muscle actin (SMA), CD31 and Desmin. Considering begin tumor, complete surgical resection is advisable, especially laparoscopic excision.

\section{Acknowledgements}

This work was supported by the International Science and Technology Cooperation Program of China under Grant No. 2015DFA11180.

\section{Disclosure}

The authors report no conflicts of interest in this work.

\section{References}

[1] Matito-Díaz, M.J., Blanco-Fernández, G., Fernández-Pérez, J. and López-Guerra, D. (2015) Leiomyoma of the Round Ligament of the Liver: Report of One Case. Rev Esp Enferm Dig, 107, 644-646. 
[2] Tsukuda, K., Furutani, S., Nakahara, S., Tada, A., Watanabe, K., Takagi, S., et al. (2008) Abscess Formation of the Round Ligament of the Liver: Report of a Case. Acta Medica Okayama, 62, 411-413.

[3] Luo, X.Z., Ming, C.S., Chen, X.P. and Gong, N.Q. (2013) Epstein-Barr Virus Negative Primary Hepatic Leiomyoma: Case Report and Literature Review. World Journal of Gastroenterology, 19, 4094-4098. https://doi.org/10.3748/wjg.v19.i25.4094

[4] Carboni, F., Valle, M., Camperchioli, I., Levi Sandri, G.B., Sentinelli, S. and Garofalo, A. (2016) Mesothelial Cyst of the Round Ligament of the Liver. Journal of Minimal Access Surgery, 12, 83-85. https://doi.org/10.4103/0972-9941.158954

[5] Perini, M.V., Fink, M.A., Yeo, D.A., Carvalho, C.A., Morais, C.F., Jones, R.M., et al. (2013) Primary Liver Leiomyoma: A Review of This Unusual Tumour. ANZ Journal of Surgery, 83, 230-233. https://doi.org/10.1111/j.1445-2197.2012.06257.x

Submit or recommend next manuscript to SCIRP and we will provide best service for you:

Accepting pre-submission inquiries through Email, Facebook, LinkedIn, Twitter, etc. A wide selection of journals (inclusive of 9 subjects, more than 200 journals)

Providing 24-hour high-quality service

User-friendly online submission system

Fair and swift peer-review system

Efficient typesetting and proofreading procedure

Display of the result of downloads and visits, as well as the number of cited articles

Maximum dissemination of your research work

Submit your manuscript at: http://papersubmission.scirp.org/

Or contact act@scirp.org 